\title{
Adult Oligodendroglioma
}

National Cancer Institute

\section{Source}

National Cancer Institute. Adult Oligodendroglioma. NCI Thesaurus. Code C4014.

An olig odendrog lioma occurring during adulthood. 